\title{
Laparoscopic Cholecystectomy - a Standardized Routine Laparoscopic Procedure: Is it Possible to Predict the Duration of an Operation?
}

\author{
A. Schneider ${ }^{1 *}$, D. Wilhelm ${ }^{1,2}$, M. Fiaschi Schneider ${ }^{1}$, T. Schuster ${ }^{3}$, M. Kriner ${ }^{3}$, \\ C. Leuxner ${ }^{4}$, S. Can ${ }^{1}$, A. Fiolka ${ }^{1}$, B. Spanfellner ${ }^{4}$, W. Sitou ${ }^{4}$, and H. Feussner ${ }^{1,2}$ \\ ${ }^{1}$ Research Group MITI, Klinikum rechts der Isar \\ ${ }^{2}$ Department of Surgery, Klinikum rechts der Isar \\ ${ }^{3}$ Institute for Medical Statistics and Epidemiology, Klinikum rechts der Isar \\ ${ }^{4}$ Department of Informatics, Chair IV: Software \& Systems Engineering \\ Technische Universität München, Munich, Germany
}

Submitted May 2010. Accepted for publication February 2011.

\begin{abstract}
In order to improve operating room efficiency, it is desirable to predict the duration of scheduled surgeries as precisely as possible. The reliability of existing predicting models is less than satisfactory. This study presents an algorithm to estimate the operating time for laparoscopic cholecystectomy, based on historical data of 312 patients, taking into account clinical parameters, diagnostic imaging, and surgeon's experience. The algorithm's accuracy was evaluated in a group of 45 patients by prospectively predicting their operating times. It was shown that increased information significantly reduced prediction error. The prediction error of our algorithm was estimated to be 17.5 minutes (95\%CI: 16.5 to 18.8 minutes), whereas that of the univariable random effect model (using solely surgeon's experience as the explanation factor) was 21.6 minutes (95\%CI: 20.3 to 23.1 minutes).
\end{abstract}

Keywords: laparoscopic cholecystectomy, operating time, operating room efficiency.

\section{INTRODUCTION}

Increased economic constraints have stimulated new strategies to further improve operating room efficiency. The aim is both to save time and resources by accelerating the throughput and improve the outcome. There is no doubt that many operating rooms (ORs) are used inefficiently, and considerable amounts of money are wasted simply because of coordinative deficits [1-3].

*Corresponding Author: Armin Schneider, Research Group MITI, Klinikum rechts der Isar der Technischen Universität München, Ismaninger Straße 22, 81675 München, Germany, Tel: +49 894140 7385, Fax: +49 89 4140 7393, E-mail: schneider@chir.med.tu-muenchen.de. Other authors: wilhelm@chir.med.tumuenchen.de; feussner@chir.med.tu-muenchen.de; m.schneider@1rz.tum.de; tibor.schuster@tum.de; monika.kriner@tum.de; leuxner@in.tum.de; spanfeln@in.tum.de; sitou@in.tum.de. 
One important issue is to estimate how long an individual surgical operation will take. OR scheduling could be more efficient if the exact duration of each surgery could be predicted in advance, which would result in an improved use of the OR and an optimized workflow for all personnel involved [4]. If OR times were known, there would be reduction in both deviation from scheduled start times and patient waiting time [5-7]. In addition, time prediction is an essential element in procedure modeling, which is currently a scientific research topic. Similar evaluations by Dexter and Ledolter [8] showed that OR scheduling could be meliorated by Bayesian prediction bounds based on historic data, if available, or by a predictive value based on scheduled OR time and its proportional uncertainty, based on that of other surgeons and procedures. Ammori et al. [9] identified prolonging factors for laparoscopic cholecystectomy, which predict an extended length of operating time (OT) $>90 \mathrm{~min}$.

No surgical procedure is performed in exactly the same way, since surgeon's experience varies [10], as anatomy varies and complications may also occur. It is therefore difficult to estimate in advance the course and duration of an individual surgical intervention, even if it is a highly standardized procedure. Laparoscopic cholecystectomy is a highly standardized and common surgical intervention. The time required to accomplish this operation is around 60 minutes, but individual cases may vary from 20 minutes to 4 or 5 hours [11].

Attempts have been made to estimate surgical times based upon historical surgical times, and it was shown that prediction bounds can be accurately calculated in cases where durations follow a log-normal distribution [12-14]; the same holds true for sophisticated computer models [11,14-19]. For effective OR management and scheduling, it would be very useful to predict the exact length of time needed for a particular operation, instead of a timeframe. In order to make a more precise prediction of the duration of this paradigmatic surgical procedure, we evaluated the significance of various clinical parameters, laboratory findings and preoperative imaging results, which are known to affect the OT [20-22]. The aim was to improve the prediction of operation duration through a more comprehensive algorithm. The algorithm validity was assessed by prospective prediction of individual OTs in a group of patients with different clinical conditions.

\section{MATERIAL AND METHODS}

This study was approved by the local Research Ethics Committee. Data of a group of 312 consecutive patients (Group A) admitted for elective laparoscopic cholecystectomy were prospectively collected and analyzed. Influences of relevant clinical parameters on OT (from skin incision to last suture), such as gender, Body Mass Index (BMI) as well as previous surgery history in upper abdomen and previous episodes of acute cholecystitis, were assessed.

Preoperatively, all patients have had at least one gallbladder sonographic examination. Two main pieces of information were collected:

- Whether the gallbladder wall thickens $(>2 \mathrm{~mm})$ or not 
- Number and size of bile calculi categorized as following:

- Category 1: calculi smaller than $5 \mathrm{~mm}$

- Category 2: calculi between 5 and $12 \mathrm{~mm}$

- Category 3: size of concrements more than $12 \mathrm{~mm}$ or numerous smaller stones ("gallbladder packed with stones")

In addition, the personal experience of the surgeon was defined. It was determined as being high ( $>1000$ laparoscopic cholecystectomy operations performed) or minor/moderate. The influence of each parameter on OT, was calculated based upon these variables. A calculation algorithm to estimate overall OT for individual cases was conceived.

OT of a second patient group (Group B, $\mathrm{n}=45$ ) was then prospectively calculated. The predicted OT was compared to the real OT and also to the historical mean hospital OT for laparoscopic cholecystectomies performed between 2003 and 2007 ( $n=837,60$ $\pm 2 \mathrm{~min}$ ). The observation period was restricted to these years to guarantee that the surgical technique was identical in all cases (a different technique was implemented before 2003). Since no conversions occurred in Group A, conversion cases were also not considered when calculating historical mean OT. To achieve meaningful results in both cases, we computed absolute values of the difference for real OT.

\section{STATISTICS}

Generalized linear mixed regression models were employed to investigate relations between OT and clinical parameters, as well as findings in diagnostic imaging. This model class was chosen to consider potential clustered effects caused by a limited number of surgeons with different surgical experiences. Due to the abnormal distribution of time measurements, the natural logarithm of the main outcome variable (OT) was taken. Thus, relative effects of potential explanatory variables were modeled. Particularly, back-transformation of estimated regression coefficients (using simple exponential function) gives the estimated factorial increase of OR time by one unit increments of the corresponding explanatory variable. Only those explanatory variables not exceeding predefined significance level of 0.05 (two-sided) were considered to be within the final prognostic model. For descriptive purposes, median OT, inter quartile range (IQR: from 25th to 75th percentile) and complete range was reported. Statistical analysis was performed using SPSS 16.0 for Windows (SPSS Inc., Chicago, IL, USA) and $\mathrm{R}$ version 2.7.1 ( $\mathrm{R}$ development Core Team (2008), URL http://www.Rproject.org).

\section{RESULTS}

\subsection{EVALUATION OF PROGNOSTIC FACTORS}

\subsubsection{Clinical parameters}

Total operating time

The median OT for Group A ( $\mathrm{n}=312)$ was $52 \mathrm{~min}$ (IQR: 42 to $68 \mathrm{~min})$ with a wide range of variation from $23 \mathrm{~min}$ to $163 \mathrm{~min}$. The mean OT basically remains constant for all patients. Neither an institutional learning curve nor a longer OT could be recognized, which is demonstrated by the constant moving average calculated out of the OTs (see Figure 1). 


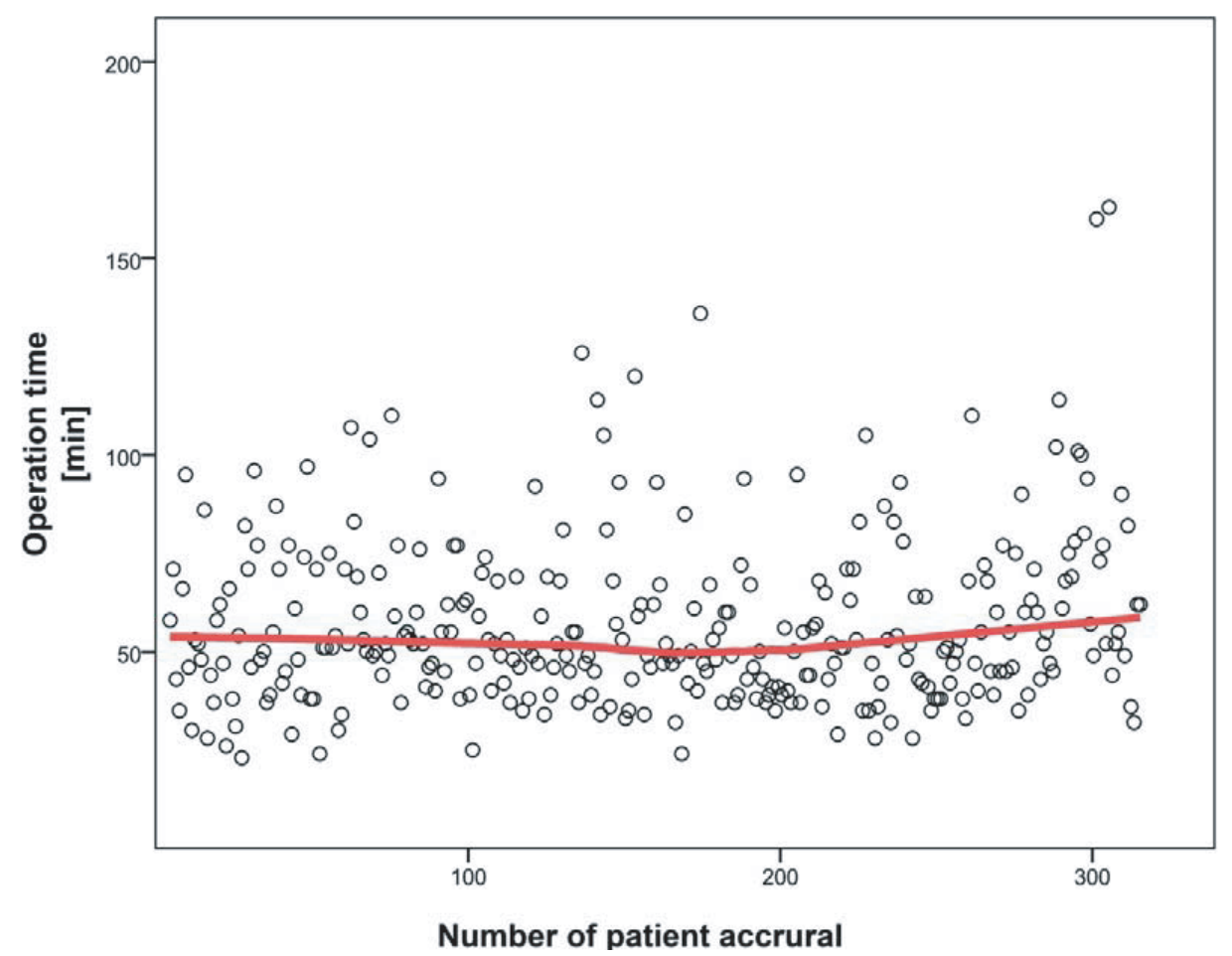

Figure 1. Distribution of operating time in Group A during each 312 individual cases. The red line indicates the moving average.

\section{Gender}

It is widely assumed that removing the gallbladder in men is more difficult than in women. However, our data analysis revealed only a slightly longer OT in men compared to women. The median OT in men $(\mathrm{n}=107)$ was $53 \mathrm{~min}$ (IQR: 45 to $75 \mathrm{~min}$, range: 24 to $160 \mathrm{~min}$ ). The median OT in women ( $\mathrm{n}=205)$ was $50 \mathrm{~min}$ (IQR: 39 to $64 \mathrm{~min}$, range: 23 to $163 \mathrm{~min}$ ).

\section{Body mass index}

A weak but nevertheless statistically significant positive correlation between BMI level and OT was identified in the data (spearman rho: $+0.22 ; \mathrm{p}<0.001$ ). Estimated (univariable) increase of OT per $1 \mathrm{~kg} / \mathrm{m}_{\text {_ }}$ was about $1 \%$.

\section{Previous surgery}

In 30 out of 312 patients, previous surgery had been performed in the upper abdomen. In most of these cases, a semi-open approach (Hasson's technique) was performed. Patients with previous operations had a median OT of $48 \mathrm{~min}$ (IQR: 42 to $60 \mathrm{~min}$, range: 31 to 110 $\mathrm{min}$ ), while that of the non-operated patient group was $52 \mathrm{~min}$ (IQR: 42 to $68 \mathrm{~min}$, range: 23 to $163 \mathrm{~min}, \mathrm{p}=0.341$ ). There was no significant difference between the two groups. 
History of acute cholecystitis

Even with one single episode of acute cholecystitis (78 patients concerned), OT was significantly longer than without (median (IQR): $71 \mathrm{~min}$ (55 to $94 \mathrm{~min}$ ) versus $48 \mathrm{~min}$ (39 to $57 \mathrm{~min}) ; \mathrm{p}<0.001$ ).

\subsubsection{Diagnostic imaging}

Thickening of gallbladder wall

Thickening of gallbladder wall was diagnosed in 88 of the total group (28\%). The difference in median OT was $20 \mathrm{~min}$ and was highly significant (median (IQR): $68 \mathrm{~min}$ (53 to $90 \mathrm{~min})$ vs. $48 \mathrm{~min}(39$ to $58 \mathrm{~min}) \mathrm{p}<0.001)$.

Number and size of bile calculi

Different categories of number and size of bile calculi were important for OT (median $(\mathrm{IQR})$ of category $1(\mathrm{n}=128): 47 \mathrm{~min}(38$ to $55 \mathrm{~min})$, category $2(\mathrm{n}=68): 52 \mathrm{~min}(42$ to $71 \mathrm{~min})$, category $3(\mathrm{n}=116): 57 \mathrm{~min}(48$ to $77 \mathrm{~min})(\mathrm{p}<0.001))$.

\subsubsection{Surgeon's experience}

It was expected that there was some association between surgeon's experience and OT. However, the difference of OT between low and moderately trained surgeons was rather small (difference in medians OT of about 3 minutes and almost equal 1st/3rd quartiles). Therefore, there was no need for differentiation. A total of 140 surgeries were performed by surgeons with minor or average experience, with a median OT of $55 \mathrm{~min}$ (IQR: 46 to $69 \mathrm{~min}$ ). In comparison, 172 cholecystectomies were performed by highly trained surgeons, where the median OT was significantly shorter with 49 min (IQR: 39 to $67 \mathrm{~min} ; \mathrm{p}=0.003)$.

\subsection{Prediction Algorithm}

Generalized linear mixed model analysis revealed a statistically significant prognostic impact of the parameters including surgeon's experience, concrement size, and BMI. According to this information, a lower level of surgeon's experience, larger concrement size, and higher BMI were associated with significant prolonged OT. Further, a significant effect of concomitant inflammation history with gallbladder wall thickening (p-value interaction: < 0.001) was demonstrated by the final regression model. Final prognostic model coefficients are displayed in Table 1. Due to the chosen log-normal model, coefficients are (re-)transformed by an exponential function to achieve corresponding estimatives of scale parameters (relative change of reference value). Explained Model variability was around $40 \%$ (r-square: 0.38 ). Estimated heterogeneity among surgeons (random effect) was rather small compared to estimated covariable effects (Table 1).

For illustration and clinical applicability, a nomogram (Figure 2) was created based on the final regression model. In this figure, model-based score points are displayed for each factor's variable category, which have to be summed for each patient. The summed total number of points is used to predict OT from the lower scale. 
Table 1. Coefficients for operating time prediction formula generation and significances for each factor.

Final log-linear mixed regression model $^{\S}$ of OT (minutes)

\begin{tabular}{|c|c|c|c|c|c|c|}
\hline & \multirow[b]{2}{*}{ coef } & \multirow[b]{2}{*}{$\begin{array}{l}\text { Std. } \\
\text { Error }\end{array}$} & \multirow[b]{2}{*}{$\begin{array}{l}\operatorname{Exp} \\
(\text { coef })^{*}\end{array}$} & \multicolumn{2}{|c|}{$\begin{array}{l}95 \% \text { confidence } \\
\text { interval exp (coef) }\end{array}$} & \multirow[b]{2}{*}{ Significance } \\
\hline & & & & $\begin{array}{l}\text { lower } \\
\text { bound }\end{array}$ & $\begin{array}{l}\text { upper } \\
\text { bound }\end{array}$ & \\
\hline Intercept & 3.735 & 0.030 & $41.9^{\#}$ & 39.5 & 44.4 & $<0.001$ \\
\hline Concrement size 2 & 0.061 & 0.042 & 1.06 & 0.98 & 1.15 & 0.142 \\
\hline Concrement size 3 & 0.122 & 0.038 & 1.13 & 1.05 & 1.22 & 0.001 \\
\hline $\begin{array}{l}\text { Surgeon's experience } \\
\text { low/medium }\end{array}$ & 0.158 & 0.032 & 1.17 & 1.10 & 1.25 & $<0.001$ \\
\hline History of inflammation - yes & 0.094 & 0.067 & 1.10 & 0.96 & 1.25 & 0.160 \\
\hline Gallbladder wall thickening - yes & 0.097 & 0.055 & 1.10 & 0.99 & 1.23 & 0.079 \\
\hline $\begin{array}{l}\text { Interaction of gallbladder wall } \\
\text { thickening and history of } \\
\text { inflammation }\end{array}$ & 0.266 & 0.091 & 1.31 & 1.09 & 1.56 & 0.004 \\
\hline BMI $\left(\mathrm{kg} / \mathrm{m}^{2}\right)$ & 0.009 & 0.003 & 1.01 & 1.00 & 1.01 & 0.001 \\
\hline
\end{tabular}

$\S$ estimated variance (random effect) of surgeons: $0.026 \pm 0.013$ (log-scale)

* Scaling factor of reference OT (\#)

\# Reference OT for a patient with BMI $=25 \mathrm{~kg} / \mathrm{m}$, concrement size $=1$, highly experienced surgeon, no history of inflammation, and no wall thickening

Prediction formula:

OT $[\mathrm{min}]=\exp [3.735+0.0614 \times($ concrement size $=2)+0.122 \times($ concrement size $=3)+$ $0.158 \times($ experience of surgeon $=0)+0.094 \times($ history of inflammation $=1)+0.097 \times$ $($ wall thickening $=1)+0.009 \times($ BMI -25$)+0.266 \times($ history of inflammation $=1 \&$ wall thickening = 1)]

\subsection{Preoperative Estimation of the Operating Time in Group B}

\subsubsection{Clinical parameter}

Total operating time

Like Group A, a wide range of OT was observed in Group B. The range of variation was from 30 to $110 \mathrm{~min}$ with a median of $56 \mathrm{~min}$ (IQR: 43 to $74 \mathrm{~min}$ ).

Gender

Interestingly, there was a considerable but statistically not significant difference, which shows that the laparoscopic cholecystectomy OT is longer in men than women. The median OT was $70 \mathrm{~min}(55$ to $80 \mathrm{~min})$ in $\mathrm{men}(\mathrm{n}=10)$, and $54 \mathrm{~min}$ (IQR: 41 to $69 \mathrm{~min})$ in women $(\mathrm{n}=35, \mathrm{p}=0.088)$. 


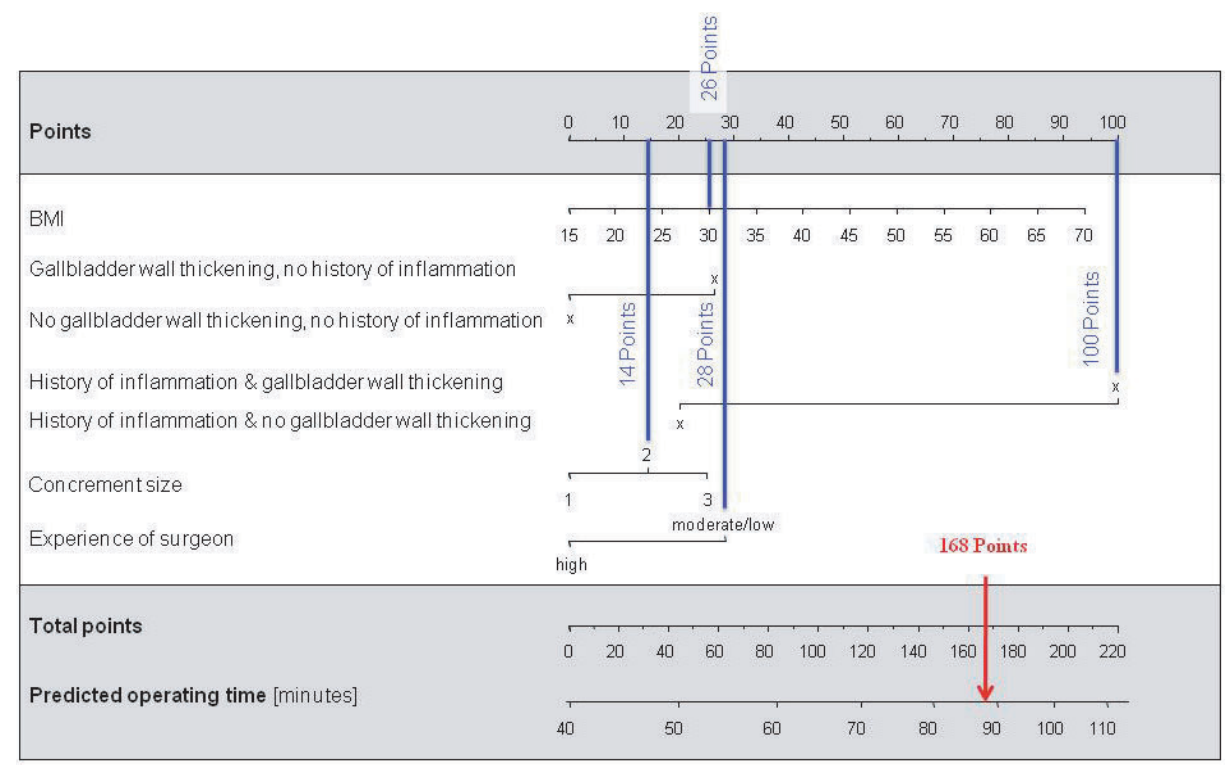

Figure 2. Nomogram for operating time prediction. To estimate the operating time (OT) for a patient, add all the corresponding points for all factors, and use the "Total points" scale to find the predicted OT on the "Predicted operating time" scale. Delineated in blue is an example: a patient with BMI $=30$, history of inflammation and gallbladder wall thickening, concrement size 2 , to be operated by a surgeon with moderate/low experience, resulting in 168 total points, corresponding to an OT of 88 minutes.

Body mass index

In this validation group, a quite similar BMI effect on OT as in Group A was estimated (model coefficient: $0.010 \pm 0.001$ ).

\section{Previous surgery}

Due to a small sample size of patients with previous surgery in the upper abdomen (n $=3$ ), the correlation between this factor and the OT could not be investigated.

\section{History of acute cholecystitis}

The data of 11 patients out of a group of 45 patients (24\%) showed that even after one single previous episode of acute cholecystitis, a significantly longer OT is required (median (IQR):78 $\mathrm{min}$ (65 to $107 \mathrm{~min}$ ) versus $52 \mathrm{~min}$ (41 to $64 \mathrm{~min}$ ); $\mathrm{p}=0.002$ ).

\subsubsection{Diagnostic imaging}

Thickening of gallbladder wall

Thickening of the gallbladder wall was diagnosed in nine patients in the validation group (Group B). A highly significant longer OT was observed in patients with thickened gallbladder wall (median (IQR): $83 \min$ (75 to $107 \mathrm{~min}$ ) vs. $52 \min$ (40 to $64 \mathrm{~min}$ ), p <0.001). 
Number and size of bile calculi

The current data demonstrated that the number and size of bile calculi category affects OT. Patients with no or small calculi $<5 \mathrm{~mm}$ (Category $1, \mathrm{n}=27$ ) had a median OT of $56 \mathrm{~min}$ (IQR: 42 to $68 \mathrm{~min}$; patients with calculi between 5 and $12 \mathrm{~mm}$ (Category 2, $\mathrm{n}$ $=7$ ) had a median OT of $41 \mathrm{~min}$ (32 to $64 \mathrm{~min}$ ); and patients with concrements $>12 \mathrm{~mm}$ or multiple small calculi (Category $3, \mathrm{n}=11$ ) showed a median OT of $74 \mathrm{~min}$ (IQR: 54 to $101 \mathrm{~min}, \mathrm{p}=0.018)$.

\subsubsection{Surgeon's experience}

Patient Group B confirms the result of Group A that the training level of the surgeon significantly influences OT. Surgeons with low and moderate training levels $(n=26)$ required about 15 minutes more to complete the surgical procedure than highly experienced surgeons (median (IQR): $62 \mathrm{~min}$ (53 to $77 \mathrm{~min}$ ) vs. $44 \mathrm{~min}$ (34 to $65 \mathrm{~min}$ ); $\mathrm{p}=0.004)$.

\subsection{Performance of Operating Time Prediction Algorithm}

For an independent evaluation of its predictive capability, the proposed prediction model (Table 1 and Figure 2) was applied to validate data of Group B. Explained variability was promising ( $\mathrm{r}$-square $=0.50$ ), as it was considerably higher than the original data set (r-square: 0.38 ). Figure 3 shows the fraction of correctly classified patients from validation sample given for several precision boundaries. A substantial fraction of OT may be correctly estimated using the present prediction algorithm, e.g., about $50 \%$ (95\% CI: $34 \%$ to $65 \%$ ) with a precision of $+/-10 \mathrm{~min}$.

The prediction error of the proposed model including that of the studied variables (BMI, acute cholecystitis history, etc.) was estimated to have a mean of $17.5 \mathrm{~min}$ (95\% CI: 16.5 to $18.8 \mathrm{~min}$ ). The error of the univariable random effect model (which only uses surgeon experience as an explanatory factor) was estimated to have a mean of 21.6 minutes (95\% CI: 20.3 to 23.1 minutes).

\section{DISCUSSION}

An important task of operating room management is to maximize the number of surgical cases performed in the OR. Unfortunately, more often than not, OR schedules are changed during the day. Also, surgical procedures may be far shorter than expected, resulting in considerable undesirable OR downtime.

Until now, the duration of an operation has been basically estimated based on empirical knowledge. Prediction has not been as precise as it is required [12], even if advanced calculation algorithms are applied [14, 23, 24]. Therefore, a better tool to predict OT would be extremely helpful. For laparoscopic operations, in particular laparoscopic cholecystectomies, a number of papers dealing with these "difficult operations" as well as the prediction of conversion have already been presented $[22,25-$ 27]. Since "difficulties" always lead practically to prolonged OR times, these studies seemed to be helpful in this context. According to the published literature, male gender obesity, inflammation history, gallbladder wall thickening, etc., may all increase the probability of conversion and lead to a longer OT [28, 29]. 


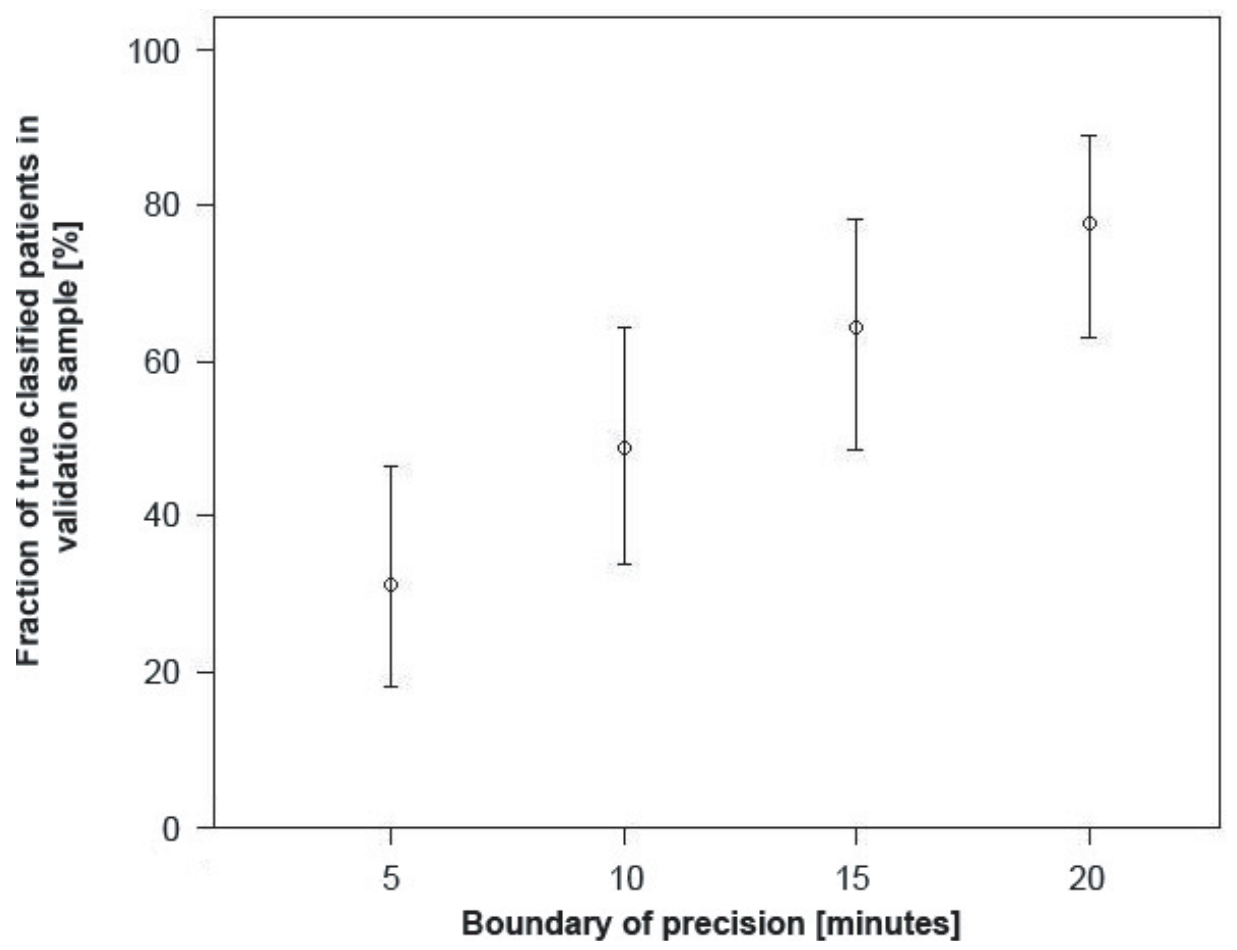

Figure 3. Predictive capability of the proposed operating time estimation algorithm for different precision boundaries. Error bars represent exact 95\% confidence limits for estimated true classification probabilities.

To our knowledge, detailed clinical information has never been integrated into the models to estimate surgical duration. Our findings confirm that individual clinical conditions are helpful to create more precise OT prediction. The improvement is considerable, as high as $32.9 \%$ compared to statistical historical average. However, predictive error can only be reduced to $17.5 \mathrm{~min}$ using our model. Compared to $21.6 \mathrm{~min}$ considering only the individual surgeon's experience, this is not as precise as expected.

Parameters such as age, gender and BMI are easy to determine, but sonographic findings are less reliable. The "thickening of the gallbladder" diagnosis was either falsely positive or falsely negative in some cases in Groups A and B. This reduced the accuracy of OT prediction. If this information had been more reliable, algorithm accuracy would have been higher. Surgeon's experience has a similarly strong influence upon OT. We often observed that surgeons with a moderate experience, generally assisted by laparoscopic experts, received additional active help from experienced laparoscopic surgeons during the operation, who took over part of operative procedures. The extent of such active supports varied widely. This, unfortunately, weakened the predictive power of this factor. 
Currently, intensive scientific activity is focused on surgical workflow modeling, and with these models, the reason for why individual operations vary considerably in duration may be answered [30]. In the majority of these approaches, detailed knowledge of surgical duration, factors which prolong intervention and consecutive surgical steps are crucial. However, this new approach will be successful only if dedicated models and algorithms are generated for each specific type of surgery and, furthermore, the intervention is highly standardized. In parallel to the prediction algorithm development, future research is required to learn whether the cost of using electronic medical record data is worthwhile, since linking different information systems is not free - in fact, keeping connections over the years can be quite expensive.

\section{CONCLUSION}

The developed algorithm for OT prediction shows that, if clinical aspects, imaging variables and surgeon training level are taken into consideration in relation to a highly standardized surgical procedure, the OT appears to become more precisely predictable. However, the benefit is actually not in a range which allows scheduling more interventions in one day compared to results based on empirical estimation.

\section{ACKNOWLEDGEMENTS}

This research was partially supported by a Deutsche Forschungsgemeinschaft grant (FE 585/1-1).

\section{REFERENCES}

[1] Rhodes RS. How much does it cost? How much can be saved? Surgery 125: 102-3, 1999.

[2] Wright JG, Roche A, Khoury AE. Improving on-time surgical starts in an operating room. Can J Surg 53: 167-70, 2010.

[3] Lebowitz P. Why Can’t My Procedures Start On Time? AORN 77: 594-7, 2003.

[4] Tyler DC, Pasquariello CA, Chen CH. Determining optimum operating room utilization. Anesth Analg 96: 1114-21, table, 2003.

[5] Dexter F, Traub RD. How to schedule elective surgical cases into specific operating rooms to maximize the efficiency of use of operating room time. Anesth Analg 94: 933-42, table, 2002.

[6] Dexter F, Epstein RH, Traub RD, Xiao Y. Making management decisions on the day of surgery based on operating room efficiency and patient waiting times. Anesthesiology 101: 1444-53, 2004.

[7] Marjamaa R, Vakkuri A, Kirvelä O. Operating room management: why, how and by whom? Acta Anaesthesiologica Scandinavica 52: 596-600, 2008.

[8] Dexter F, Ledolter J. Bayesian prediction bounds and comparisons of operating room times even for procedures with few or no historic data. Anesthesiology 103: 1259-167, 2005.

[9] Ammori BJ, Larvin M, McMahon MJ. Elective laparoscopic cholecystectomy: preoperative prediction of duration of surgery. Surg Endosc 15: 297-300, 2001.

[10] Strum DP, Sampson AR, May JH, Vargas LG. Surgeon and type of anesthesia predict variability in surgical procedure times. Anesthesiology 92: 1454-66, 2000.

[11] Dexter F, Davis M, Halbeis CE, Marjamaa R, Marty J, McIntosh C, Nakata Y, Thenuwara KN, Sawa T, Vigoda M. Mean operating room times differ by $50 \%$ among hospitals in different countries for laparoscopic cholecystectomy and lung lobectomy. Journal of Anesthesia 20: 319-22, 2006.

[12] Zhou J, Dexter F, Macario A, Lubarsky DA. Relying solely on historical surgical times to estimate accurately future surgical times is unlikely to reduce the average length of time cases finish late. J Clin Anesth 11: 601-5, 1999. 
[13] Zhou J, Dexter F. Method to assist in the scheduling of add-on surgical cases-upper prediction bounds for surgical case durations based on the log-normal distribution. Anesthesiology 89: 1228-32, 1998.

[14] Spangler WE, Strum DP, Vargas LG, May JH. Estimating procedure times for surgeries by determining location parameters for the lognormal model. Health Care Manag Sci 7: 97-104, 2004.

[15] Sorge M. Computerized O.R. scheduling: is it an accurate predictor of surgical time? Can Oper Room Nurs J 19: 7-18, 2001.

[16] Pandit JJ, Carey A. Estimating the duration of common elective operations: implications for operating list management. Anaesthesia 61: 768-76, 2006.

[17] Shukla RK, Ketcham JS, Ozcan YA. Comparison of subjective versus data base approaches for improving efficiency of operating room scheduling. Health Serv Manage Res 3: 74-81, 1990.

[18] Devi SP, Rao KS, Sangeetha SS. Prediction of Surgery Times and Scheduling of Operation Theaters in Optholmology Department. J Med Syst 2010.

[19] Olivares M, Terwiesch C, Cassorla L. Structural Estimation of the Newsvendor Model: An Application to Reserving Operating Room Time. Management Science 54: 41-55, 2008.

[20] Hutchinson CH, Traverso LW, Lee FT. Laparoscopic cholecystectomy. Do preoperative factors predict the need to convert to open? Surg Endosc 8: 875-8, 1994.

[21] Greenwald JA, McMullen HF, Coppa GF, Newman RM. Standardization of surgeon-controlled variables: impact on outcome in patients with acute cholecystitis. Ann Surg 231: 339-44, 2000.

[22] Gholipour C, Fakhree M, Shalchi R, Abbasi M. Prediction of conversion of laparoscopic cholecystectomy to open surgery with artificial neural networks. BMC Surgery 9: 13, 2009.

[23] Dexter F, Epstein RH, Lee JD, Ledolter J. Automatic updating of times remaining in surgical cases using bayesian analysis of historical case duration data and "instant messaging" updates from anesthesia providers. Anesth Analg 108: 929-40, 2009.

[24] Eijkemans MJC, van Houdenhoven M, Nguyen T, Boersma E, Steyerberg EW, Kazemier G. Predicting the Unpredictable: A New Prediction Model for Operating Room Times Using Individual Characteristics and the Surgeon's Estimate. Anesthesiology 112: 2010.

[25] Fuchs KH, Freys SM, Heimbucher J, Thiede A. [Laparoscopic cholecystectomy - what is the value of laparoscopic technique in "difficult" cases?]. Chirurg 63: 296-304, 1992.

[26] Kama NA, Doganay M, Dolapci M, Reis E, Atli M, Kologlu M. Risk factors resulting in conversion of laparoscopic cholecystectomy to open surgery. Surg Endosc 15: 965-8, 2001.

[27] Pavlidis TE, Marakis GN, Ballas K, Symeonidis N, Psarras K, Rafailidis S, Karvounaris D, Sakantamis AK. Risk Factors Influencing Conversion of Laparoscopic to Open Cholecystectomy. Journal of Laparoendoscopic \& Advanced Surgical Techniques 17: 414-8, 2007.

[28] Eldar S, Sabo E, Nash E, Abrahamson J, Matter I. Laparoscopic cholecystectomy for the various types of gallbladder inflammation: a prospective trial. Surg Laparosc Endosc 8: 200-7, 1998.

[29] Simopoulos C, Botaitis S, Karayiannakis AJ, Tripsianis G, Pitiakoudis M, Polychronidis A. The contribution of acute cholecystitis, obesity, and previous abdominal surgery on the outcome of laparoscopic cholecystectomy. Am Surg 73: 371-6, 2007.

[30] Neumuth T, Jannin P, Schlomberg J, Meixensberger J, Wiedemann P, Burgert O. Analysis of surgical intervention populations using generic surgical process models. Int J Comput Assist Radiol Surg 6(1):59-71, 2011. 



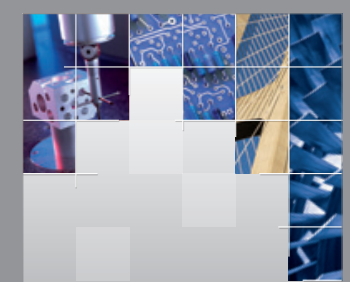

\section{Enfincering}
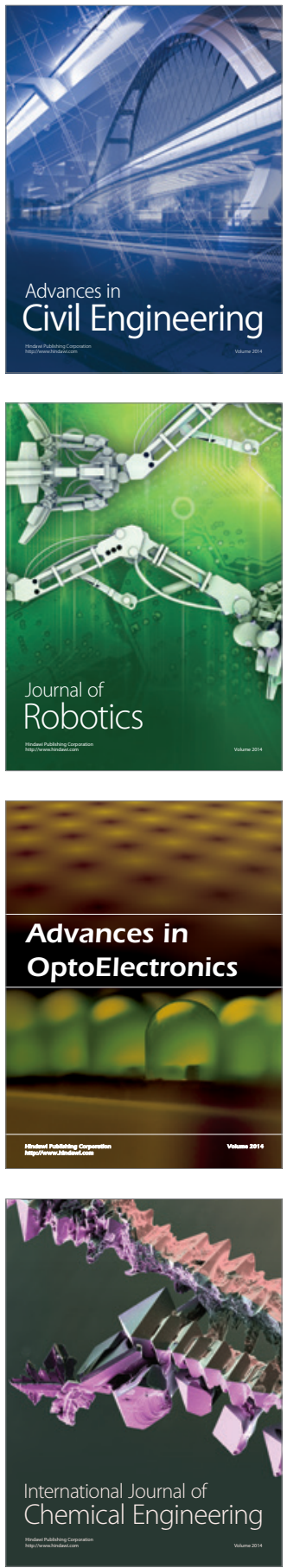

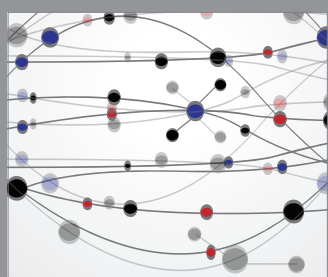

The Scientific World Journal

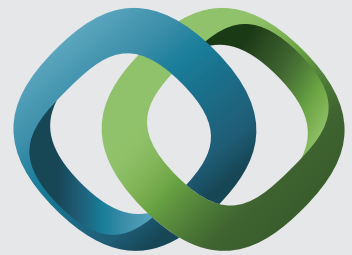

\section{Hindawi}

Submit your manuscripts at

http://www.hindawi.com
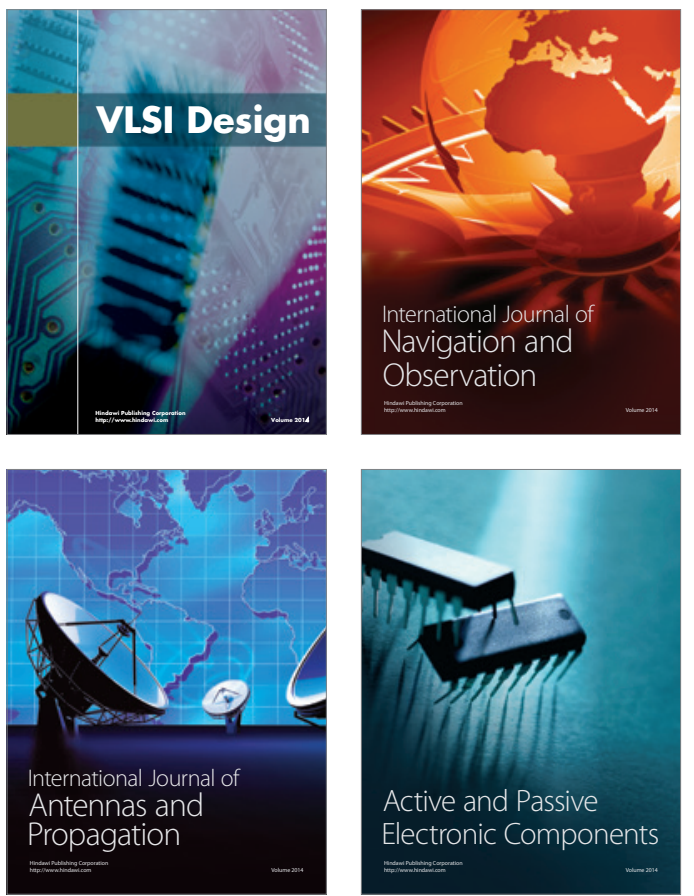
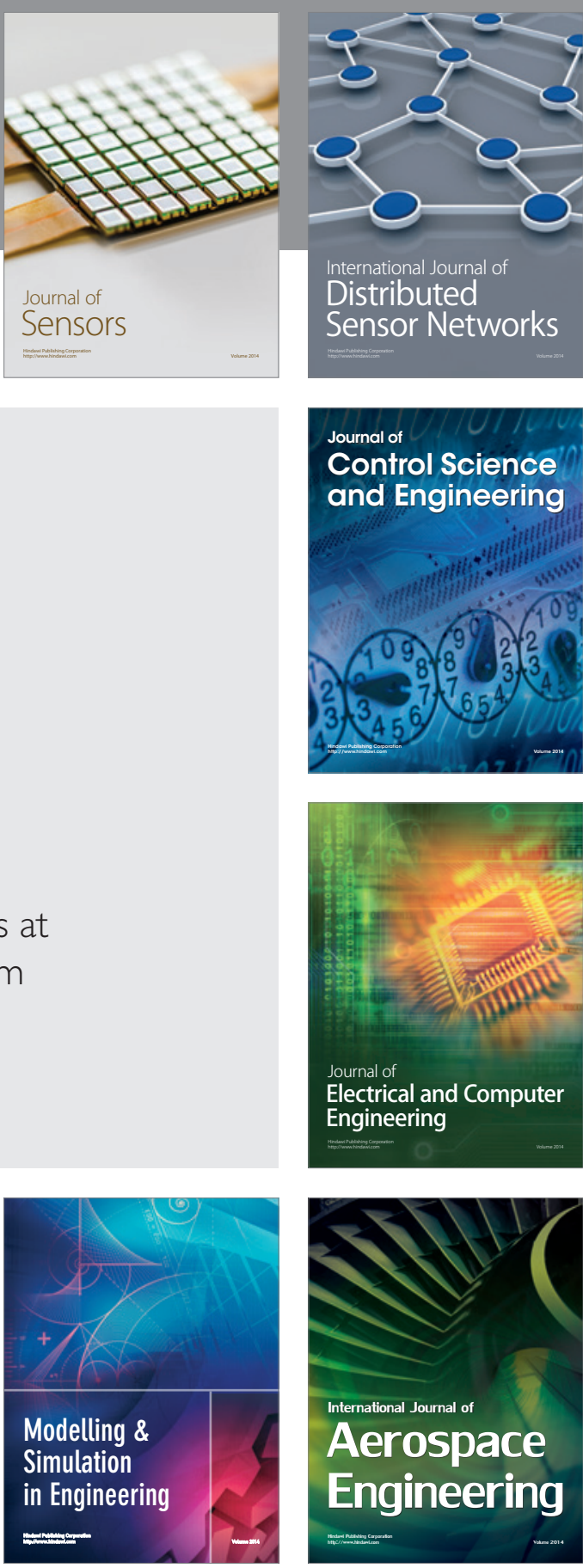

International Journal of

Distributed

Sensor Networks

Journal of

Control Science

and Engineering
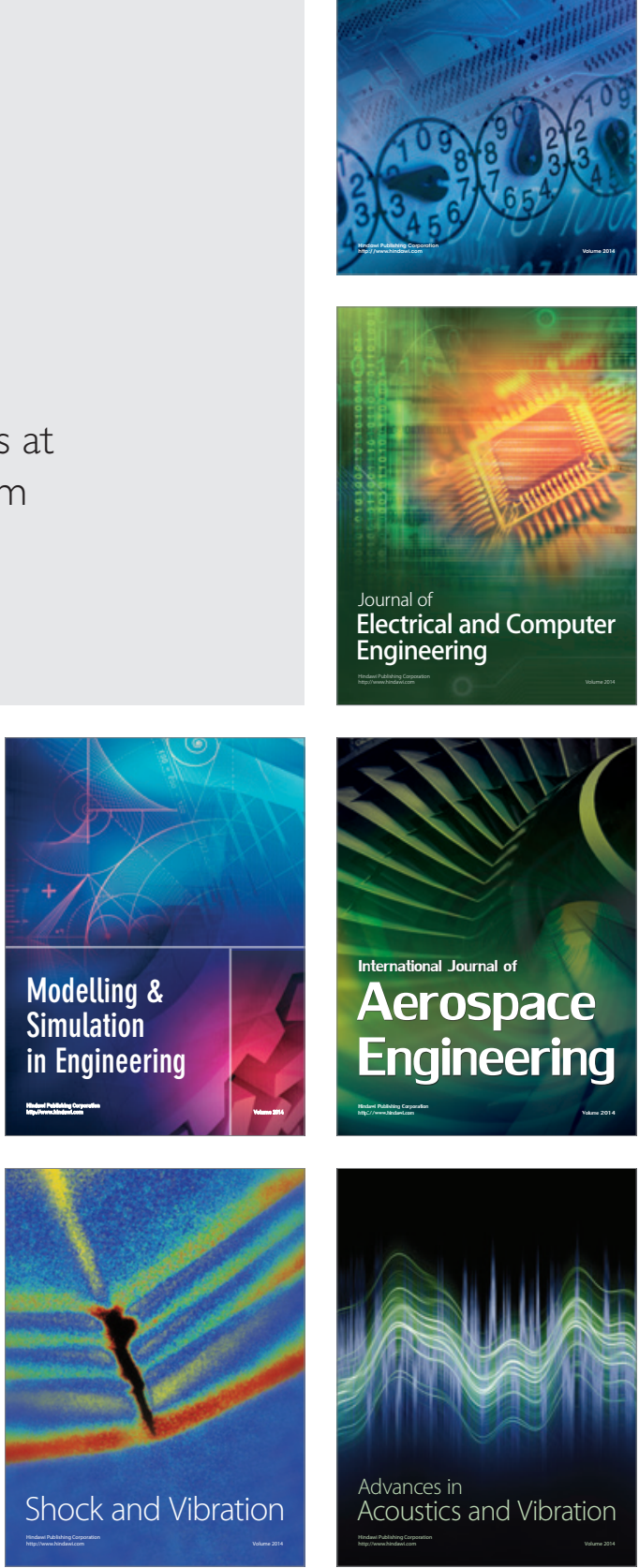